\title{
The Unpacked Influence of Personality Traits on Personal and Academic Attributes Among Students
}

\author{
Ejaz Ahmed Khan \\ International Islamic University Islamabad
}

\begin{abstract}
Individual differences have a great significance in learning and educational practice. The present study primarily inspected the relationship among personality traits, academic selfefficacy, academic self-concept, satisfaction with life and meaning in life among students. Moreover, this research also examines the impact of personality traits (extrovert, agreeableness, conscientiousness, emotional stable, openness to experience) on academic self-concept in male and female students. Students from different Universities of Islamabad were engaged $(\mathrm{N}=130)$. Purposive sampling technique was implemented for data collection and five scales were used to measure the study variables. The findings revealed that Extrovert and Agreeableness were positively significant with academic self-efficacy, academic self-concept, satisfaction with life and meaning in life. The findings also shown that Conscientiousness and Emotional stable were positively significant associated with academic self-concept. These analyses displayed that Openness to experience was positively significant linked to academic self-concept. Academic selfconcept has significantly positive related to meaning in life. Satisfaction with life has significantly positive correlation with meaning in life. Further, results revealed that Emotional stable was negatively significant predicting to academic self-concept $(\beta=-.33, p>.01)$ in male students. Likewise, the finding also revealed that this trait of personality was negatively non-significant predicting to academic self-concept $(\beta=-.12, n . s)$ in female students. Openness to experience was positively non-significant predicting to academic self-concept $(\beta=.09, n . s)$ in male students. On other hand, findings revealed that this trait was negatively significant predicting to academic selfconcept $(\beta=-.32, p>.01)$ in females students. Study analysis also revealed that Conscientiousness was negatively non-significant predicting to academic self-concept $(\beta=-.207, n . s)$ in female students. However, results displayed that this trait of the personality was positively significant predicting to academic self-concept $(\beta=.309, p>.01)$ in male students. This study would be helpful in educational environment to inspire and cherish students' motivation and achievement, particularly related to the personality traits involved in the cognitive performance in terms of academic achievement, self-efficacy and self-concept.
\end{abstract}

Key Words: Agreeableness, Conscientiousness, Emotional Stable, Meaning in Life, Satisfaction with life 